\title{
Assessment of serum 25-Hydroxyvitamin D concentrations in post-menopausal osteoporotic women: a retrospective study to evaluate long-term treatment with vitamin $\mathbf{D}_{3}$
}

Camilla Sand Andersen ${ }^{1,2}$, Peter Vestergaard ${ }^{1}$, Parisa Gazerani ${ }^{1}$, Hans Christian Hoeck ${ }^{2}$. ${ }^{1}$ Department of Health Science and Technology, Faculty of Medicine, Aalborg University, Denmark. ${ }^{2}$ CCBR, Denmark.

\section{Introduction}

Circulating concentrations of 25-hydroxyvitamin $\mathrm{D}(25(\mathrm{OH}) \mathrm{D})$ are considered the best indicator of vitamin D status [1].

- However, the optimal concentration of $25(\mathrm{OH}) \mathrm{D}$ required for maintenance of skeletal integrity has been a matter of debate.

- Another question yet unanswered is how much vitamin $D$ we need to produce or digest in order to achieve an optimal serum 25(OH)D. The clinical evidence is far from clear [2]

- The aim of this study was to evaluate whether daily treatment with $400 \mathrm{IU}$ vitamin $\mathrm{D}_{3}$ was sufficient to maintain $25(\mathrm{OH}) \mathrm{D}$ concentrations above $60 \mathrm{nmol} / \mathrm{L}$ over a threeyear period.

In addition, the study aimed to clarify if any differences existed in serum 25(OH)D between pre-supplemented women and women who already had serum $25(\mathrm{OH}) \mathrm{D}$ above $60 \mathrm{nmol} / \mathrm{L}$ at screening.

\section{Methods}

A retrospective single-center study was designed to evaluate $25(\mathrm{OH}) \mathrm{D}$ serum concentrations in 251 menopausal women over a three-year period using data collected from a randomized, double-blind, placebo-controlled osteoporosis study.

A comprehensive patient file review was performed to collect patient characteristics and laboratory results. Furthermore, $25(\mathrm{OH}) \mathrm{D}$ baseline concentrations were used to classify pre-supplemented women (Group 1) and non-pre-supplemented women (Group 2)

Stored serum samples obtained 6, 12, 24 and 36 months after screening were identified and collected for both groups.

\begin{tabular}{|c|c|c|c|c|}
\hline CHARACTERISTIC & ALL WOMEN & GROUP $1^{2}$ & GROUP $2^{2}$ & $p$ \\
\hline Participants, $\mathrm{n}^{3}$ & $251(100 \%)$ & 79 (31.5\%) & $172(68.5 \%)$ & - \\
\hline Age (year) & $68.4 \pm 6.2$ & $69.2 \pm 4.5$ & $68.0 \pm 6.9$ & 0.36 \\
\hline $\mathrm{BMI}\left(\mathrm{kg} / \mathrm{m}_{2}\right)$ & $25.2 \pm 3.8$ & $26.6 \pm 4.2$ & $24.6 \pm 3.5$ & $<0.001^{*}$ \\
\hline Smoking, yes, $\mathrm{n}^{3}$ & $32(12.8 \%)$ & $9(11.4 \%)$ & $23(13.4 \%)$ & 0.66 \\
\hline Physical Activity, yes, $n^{3}$ & $176(70.7 \%)$ & $54(69.2 \%)$ & $122(71.3 \%)$ & 0.80 \\
\hline$\geq 1$ Fracture $(\mathrm{s}), \mathrm{n}^{3}$ & $164(65.3 \%)$ & $49(62 \%)$ & $115(66,9 \%)$ & 0.46 \\
\hline$\geq 1$ Osteoporotic Fracture(s), $\mathrm{n}^{3}$ & $107(42.6 \%)$ & $27(34.2 \%)$ & $80(46.5 \%)$ & 0.07 \\
\hline Triglycerides $(\mathrm{mmol} / \mathrm{L})$ & $1.14 \pm 0.50$ & $1.40 \pm 0.62$ & $1.02 \pm 0.42$ & $<0.001^{*}$ \\
\hline Total Cholesterol (mmol/L) & $5.74 \pm 1.03$ & $5.86 \pm 0.10$ & $6.69 \pm 1.05$ & 0.11 \\
\hline Creatinine $(\mathrm{mmol} / \mathrm{L})$ & $0.07 \pm 0.01$ & $0.07 \pm 0.01$ & $0.07 \pm 0.01$ & 0.82 \\
\hline
\end{tabular}

Table 1. ${ }^{1}$ Except where indicated, data are presented as the mean \pm SD with the Mann-Whitney Test or $x^{2}$-test performed where appropriate. ${ }^{2}$ Group 1; presupplemented women. Group 2; non-pre-supplemented women. ${ }^{3}$ Data are listed as n, number of participants with $\mathrm{n}$ in percentage of total $\mathrm{n}$ in parentheses.

Serum samples stored on site at $-20^{\circ} \mathrm{C}$ from the 251 women who completed the study were analyzed for $25(\mathrm{OH}) \mathrm{D}$, parathyroid hormone $(\mathrm{PTH})$, and phosphate. RMANOVA was applied to evaluate treatment effect over time.

\section{Results}

Table 2 presents the results of long-term treatment effects of vitamin $D_{3}$ analyzed by RM-ANOVA. The mean concentration of $25(\mathrm{OH})$ D showed a significant increasing trend throughout the three-year study period and peaked at month 36 at a mean concentration of $103.5 \pm 23.0 \mathrm{nmol} / \mathrm{L}(p<0.001)$. The average increase in $25(\mathrm{OH}) \mathrm{D}$ concentrations over 36 months was $24 \mathrm{nmol} / \mathrm{L}$.

Table 2. Effects of Daily Treatment with 400 IU vitamin $D_{3}$ over Three Years

\begin{tabular}{lcccccc}
\hline Variable & BASELINE & $\mathbf{6}$ MONTHS & 12 MONTHS & 24 MONTHS & 36 MONTHS & $\boldsymbol{p}$ \\
\hline 25(OH)D (nmol/L) & $79.5 \pm 17.3$ & $93.0 \pm 19.3$ & $99.8 \pm 21.8$ & $99.4 \pm 22.0$ & $103.5 \pm 23.0$ & $0.001^{*}$ \\
Calcium (mmol/L) & $2.33 \pm 0.09$ & $2.31 \pm 0.10$ & $2.33 \pm 0.10$ & $2.33 \pm 0.08$ & $2.36 \pm 0.09$ & $<$ \\
PTH (pg/mL) & $43.9 \pm 12.0$ & $44.7 \pm 17.3$ & $44.7 \pm 15.5$ & $47.0 \pm 16.6$ & $44.2 \pm 16.1$ & $0.001^{*}$ \\
Phosphate (nmol/L) & - & $1.1 \pm 0.2$ & $1.2 \pm 0.6$ & $1.1 \pm 0.1$ & $1.1 \pm 0.1$ & 0.12 \\
Alk Phos (U/L) & $182 \pm 59$ & $163 \pm 42$ & $159 \pm 44$ & $162 \pm 45$ & $165 \pm 44$ & $<$ \\
\hline
\end{tabular}

Table 2. All values are mean \pm standard variation. $25(\mathrm{OH}) \mathrm{D}$; 25-hydroxyvitamin $\mathrm{D}$, PTH; parathyroid hormone, Alk Phos; alkaline phosphatase.

\section{Results (cont.)}

Pre-supplemented women had a significantly lower mean $25(\mathrm{OH}) \mathrm{D}$ concentration compared to non-pre-supplemented women $(p<0.001)$ as depicted in Fig. 1. Season significantly interacted with $25(\mathrm{OH}) \mathrm{D}$ concentrations over time $(p<0.001)$ and concentrations measured during winter time were significant elevated compared to the remaining seasons $(p<0.05$, Fig. 2). $25(\mathrm{OH}) \mathrm{D}$ concentrations were dependent of $\mathrm{BMI}$ $(p<0.05)$.

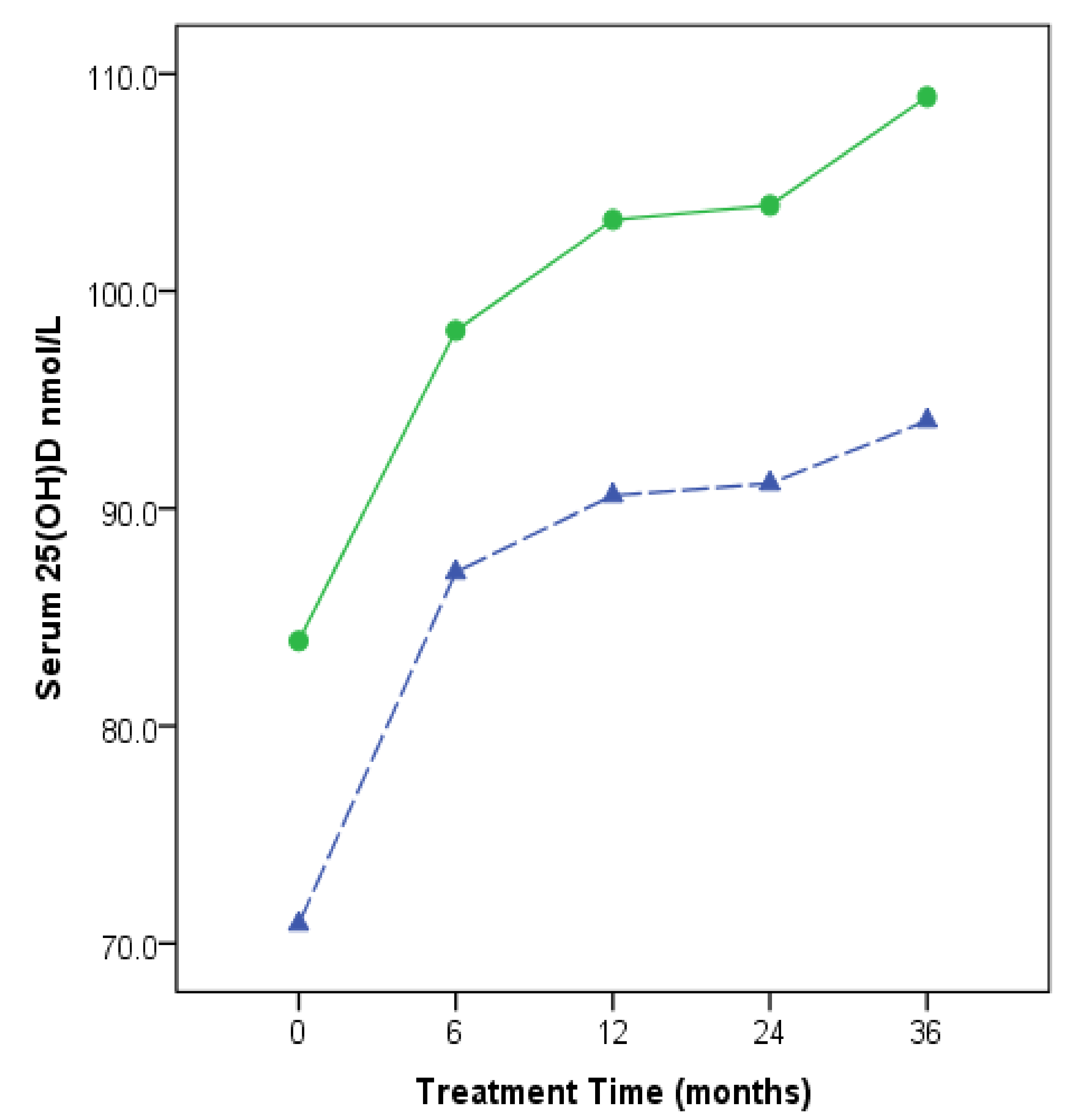

Fig. 1. Serum $25(\mathrm{OH}) \mathrm{D}$ in $\mathrm{nmol} / \mathrm{L}$ for pre-supplemented women $(-\mathbf{\Delta}-)$ and women with adequate serum $25(\mathrm{OH}) \mathrm{D}$ above $60 \mathrm{nmol} / \mathrm{L}$ prior to baseline (screening) (--).

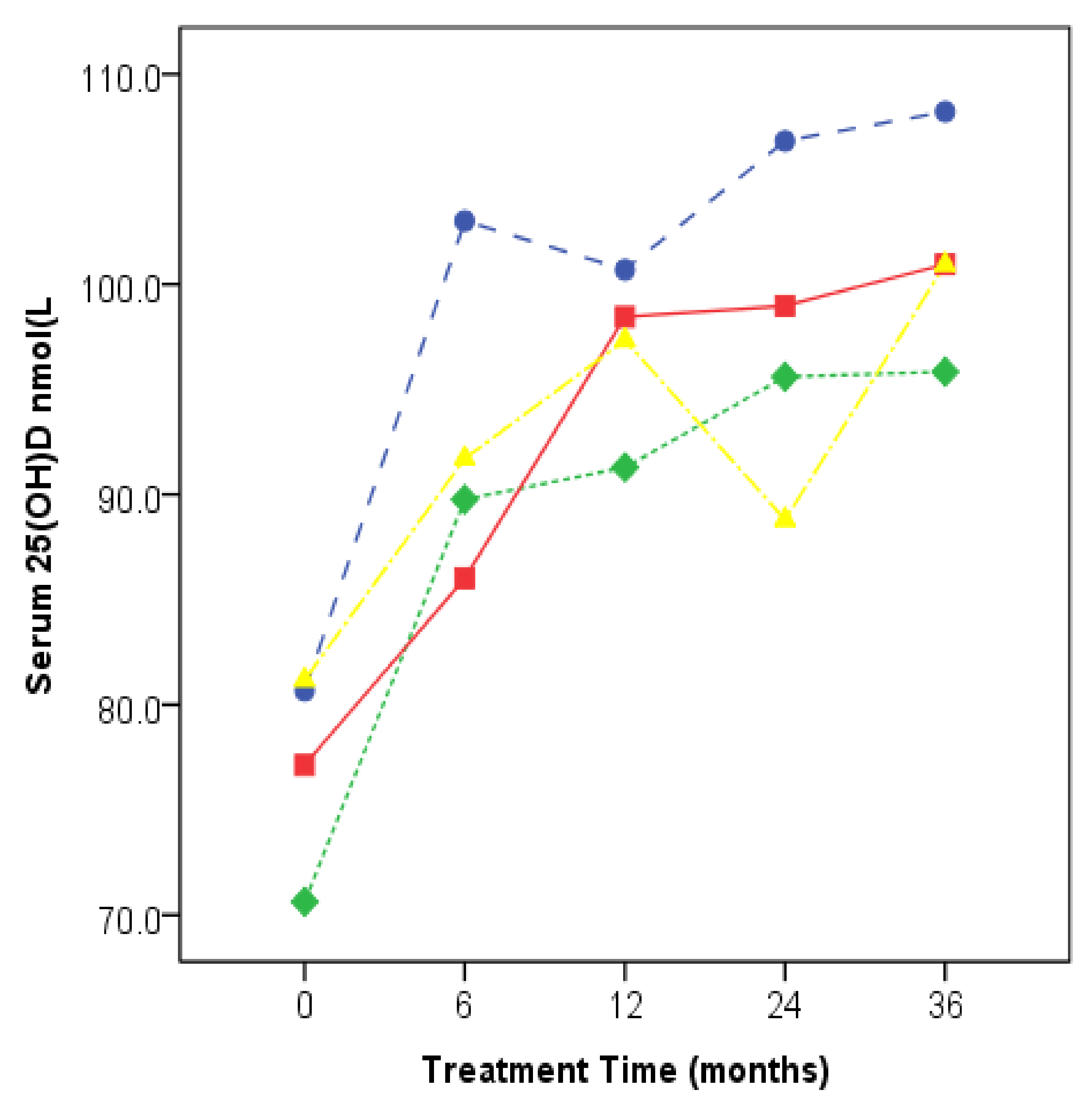

Fig. 2. Serum $25(\mathrm{OH}) \mathrm{D}$ in blood samples obtained during winter (-------), spring

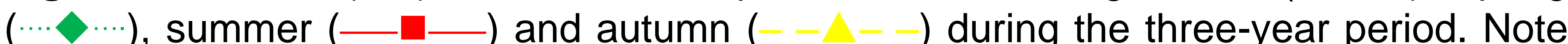
that serum samples taken at month 6 were obtained during the opposite season compared to the yearly samples.

\section{Conclusion}

In summary, our retrospective study demonstrated that after achieving a serum $25(\mathrm{OH}) \mathrm{D}$ of $60 \mathrm{nmol} / \mathrm{L}$, daily treatment with $400 \mathrm{IU}$ vitamin D3 is safe and preserves 25(OH)D serum concentrations above the threshold defined.

\section{References \& Acknowledgements}

[1] Zerwekh, J.E., Blood biomarkers of vitamin D status. Am J Clin Nutr, 2008. 87(4): $p$. 1087S-91S.

[2] Bischoff-Ferrari, H.A., et al., Estimation of optimal serum concentrations of 25hydroxyvitamin D for multiple health outcomes. Am J Clin Nutr, 2006. 84(1): p. 18-28.

Conflict of Interest Camilla S. Andersen: affiliated to Aalborg University in Denmark to conduct clinical research and employed by Center for Clinical \& Basic Research (CCBR). Peter Vestergaard and Parisa Gazerani: affiliated to Aalborg University in Denmark to conduct clinical research for the Faculty of Medicine. Hans C. Hoeck: employed by CCBR, a private re-search company engaged in contract research with various pharmaceutical and biotech companies. 